\title{
Е.А. Церковникова
}

\section{ВЗАИМОДЕЙСТВИЕ МУЗЕЯ И МЕСТНОГО СООБЩЕСТВА НА ЧУКОТКЕ В 1930-1950-е гг.}

\begin{abstract}
Рассматривается история взаимодействия музея и местного сообщества в период создания первого музея на Чукотке. Анализируются особенности сотрудничества специалистов музея с коренным населением в 1930-1950-е гг. На основе архивных материалов раскрываются особенности работы музея и участия коренных жителей в его мероприятиях, когда в сложный период для Чукотки музей как новая в регионе форма сохранения памятников истории и культуры стал центром сбора ценных знаний.

Ключевые слова: отечественная культурная традиция; музейная потребность; коренные народы Севера; советская эпоха; археологические экспедиции; Чукотка.
\end{abstract}

Последние десятилетия региональные музеи целенаправленно взаимодействуют с местными сообществом, стараются привлечь посетителей и расширить аудиторию. В крупных музеях стратегию музейной деятельности разрабатывают специалисты по музейному менеджменту и маркетингу. Для прогнозирования спроса на музейные мероприятия музеи проводят социологические исследования по изучению целевых групп. Музейные социологи изучают потребности посетителей в получении историко-культурной информации и о восприятии ими экспозиционного материала. Результаты таких исследований дают представление о реальных предпочтениях аудитории и позволяют музеям планировать свою деятельность и привлекать музейных посетителей. В отдельных, особенно удаленных от центра регионах, коммуникация музея с местными сообществами и другими категориями посетителей имеет свои особенности и уже длительную историю.

Свою специфику имеют местные сообщества представителей традиционных культур северных народов. Посетители музея - представители традиционных культур по-особому воспринимают музейную информацию о культуре своего этноса. Эта особенность восприятия связана с тем, что у многих народов традиции ещё живы и процесс изготовления, сохранения традиционных предметов применяется в повседневной жизни. Представители старшего поколения коренных народов Севера являются хранителями традиционных знаний и даже могут выступать консультантами или экспертами по этнографическим вопросам. Их разъяснение значения этнографического предмета раскрывает тонкости традиционной культуры северных народов. Пожилые северяне являются также свидетелями межэтнических интеграций и различных форм диалога культур в советский период. Молодое поколение коренных народов иначе воспринимает культуру своих предков, так как многие традиционные знания утрачены. Музей в такой ситуации способен сыграть связующую роль между поколениями.

Цель статьи - раскрыть историю взаимодействия музея и местного сообщества на Чукотке. Для решения поставленной цели предполагается решить следующие задачи: проанализировать источники по истории создания первого музея на Чукотке, описать особенности диалога культур в период первых музейных археологических экспедиций. Объектом исследования является сфера взаимодействия музея и местного сообщества Чукотки в 1930-1950-е гг. Объект включает в себя профессиональное и повседневное общение музейных сотрудников с коренным населением Чукотки.

Традиционная культура северных народов, проживающих на Чукотке, подробно раскрыта в работах исследователей В.Г. Богораза [1], В.И. Иохельсона [2], В.В. Леонтьева [3]. Исследователи установили, что автохтонное население Севера осуществляло производство, сбор и хранение бытовых и иных предметов одежды, орудий труда по сформированным веками законам и традициям. В связи с дефицитом материала - сырья и ручными технологиями изготовления утилитарных вещей практиковалось бережное их использование и хранение. Культовые предметы: личные охранители, обереги, предметы для совершения обряда, семейные охранители, наделялись охранительными свойствами, хранились и передавались следующему поколению. Кроме того, развивалась духовная культура или нематериальные знания, которые приобретались опытным путем и также передавались из поколения в поколение.

Коллективная монография «История Чукотки с древнейших времен до наших дней», опубликованная в 1989 г., раскрывает историю Чукотки, начиная с каменного века до конца 1980-х гг. [4]. В данной работе освещена история древнего заселения северных территорий человеком, формирование северных этносов, период открытия и освоение территории Чукотки российским государством. Особое внимание уделено советскому строительству на Чукотке, задачи и пути его достижении, освещается деятельность культурнопросветительных учреждений и участие в их работе коренного населения. Упоминается о создании в Анадыре музея и сборе первой коллекции [4. С. 179]. Однако вопросы, касающиеся диалога культур в советский период, рассматриваются с позиции идеологии тех времен.

Исследователи И.С. Вдовин [5], Г.С. Дьячкова [6] также обращаются к осмыслению этносоциальных процессов чукотского этноса. В их работах раскрыты взаимоотношения разных народов на Чукотке, которые строились на взаимовыгодных условиях. Север- 
ные народы перенимали друг у друга способы жизнедеятельности в тундровых и приморских условиях, а пришлое население опыт коренных народов в способах выживания в условиях Севера.

Коллекции, собранные археологами, историками, этнографами и сотрудниками музеев Москвы [7], Ленинграда [8], Магадана [9] в советский период становятся базой для изучения традиционной культуры северных народов и остаются востребованными для современных исследователей. Работы исследователей дают сведения об информантах - коренных жителях, помогавших собирать материал по темам исследования.

История музейного дела в советский период анализируется в работах историков и музееведов страны $[10,11]$. Этнографической науке в музее посвящены исследования Т.В. Станюкович [12]. Анализ специфики деятельности музеев, возникших в первые годы социалистических преобразований на Крайнем Севере, проведен Л.А. Чуриловой [13]. Автор подробно рассматривает деятельность музеев на материалах народностей Севера Средней Сибири. Вывод автора о том, что «музей в автономных округах попрежнему находится в центре диалога культур, активно пытаясь привлечь внимание к утраченным ценностям традиционной культуры северных народов», в настоящее время актуален для музеев Чукотки [Там же. С. 7]. Культурно - исторический анализ развития музейного дела на Чукотке проведен в исследовании И.И. Романовой [14]. В данной работе проанализирована история сбор коллекций на Чукотке для центральных, дальневосточных и зарубежных музеев, организация и история деятельности Чукотского окружного краеведческого музея до 1970-х гг. В исследовании так же подробно освещается создание районных музеев, проводится анализ деятельности окружного музея за период с 2001 по 2006 г. В работе автора встречаются сведения о взаимодействии музея и местного населения, но они касаются современного периода.

Ко времени становления советской власти на Чукотке происходили события, постепенно менявшие жизнь аборигенов Севера. События советского времени стали новым этапом и в развитии музеев страны. В 1930 г., после Первого Всероссийского музейного съезда, деятельность музеев была направлена на участие в культурной революции и отражение успехов социалистического строительства государства. На Чукотке в этот год произошли два важных события. Был образован Чукотский национальный округ с окружным центром в поселке Анадырь. И здесь же создается первый государственный музей. Одновременно в регионе разворачивается крупное строительство, появляются промышленные предприятия, создаются учреждения образования и культуры. Комитет Севера создает политико-просветительные учреждения (культурные базы) с целью оказания помощи в экономической и культурной жизни «малым народам» [15. С. 87]. Культбазы считались своеобразными центрами в отдаленных местах региона, где размещались медицинские, культурно-просветительные, ветеринарные пункты. На культбазах работали и краеведы, которые вели научно-исследовательскую деятель- ность по изучению истории и культуры кочевых народов [15. С. 120]. Музей развивался своим путем и нарабатывал совершенно новый опыт коммуникации, особое место в которой занимал диалог культур, в том числе в области совместного познания традиционных культур северных народов.

Реконструкция истории первого государственного музея на Чукотке в данной статье проведена с помощью исследования источников, хранящихся в Государственном архиве Чукотского автономного округа [16]. Архивные материалы позволили проанализировать информацию о деятельности музея за исследуемый период, понять условия жизни и работы его руководителей. Статистика посещения музея представлена в документах, к сожалению, фрагментарно, так как документация, видимо, терялась или велась недобросовестно в связи с частой сменой руководителей. Переписка музея с разными учреждениями показывает общее направление работы всех музеев страны в советское время. Проанализированы документы, касающиеся деятельности руководителей музея, так или иначе связанной с посетителями. Воспоминания родных руководителей музея, найденные в периодической печати и в интернете, позволили выявить их профессиональный подход в общении с окружающими и настроение того времени. Источники позволили также проанализировать роль музея в проведении археологических разведывательных экспедиций в 1950-е гг. В сохранившихся дневниковых записях участников экспедиций содержатся сведения о формах общения с коренными жителями во время профессиональной деятельности и в повседневных ситуациях. Ниже подробнее рассмотрены некоторые данные, полученные из материалов архива.

Как отмечалось выше, Чукотский национальный округ с окружным центром в поселке Анадырь был образован в 1930 г. [17. С. 5]. Однако в 1923 г. Чукотка уже принимала участие во Всероссийской сельскохозяйственной выставке, организованной в г. Москве. Предметы не успели доставить ко дню проведения мероприятия и их выставили в школе г. Петропавловск-Камчатский. Выставка «экспонатов Чукотско-Анадырского края была устроена 26 октября 1923 г. в школе и продолжалась два дня. Пятьдесят экспонатов по зоологии, геологии, этнографии края вошли в состав коллекции естественного кабинета» [18. С. 27]. В 1934 г. в Ленинграде организуется выставка Академии наук и публикуется «Краткий путеводитель к выставке «Чукотское общество» [19].

На Чукотке после Первого общероссийского музейного съезда организовали Бюро краеведения [20]. Постановлением Оргкомитета Бюро краеведения от 14.11.1931 г. было предложено действующим в округе организациям внести средства на развитие музея. Были направлены письма о сборе средств для будущего музея в Акционерное Камчатское общество, в Морагенство, в Анадырский кооператив [16. Д. 2. Л. 13]. Строительной организации было заказано «десять шкафов, застекленные с трех сторон с внутренними четырьмя полками, и небольшой шкаф 1,0 × $0,7 \times 0,8$ м» [Там же. Л. 4]. 
В первые годы музей, по-видимому, редко посещали. В поселке Анадырь на момент создания музея насчитывалось 74 хозяйства [20]. Под музей отвели маленький домик, построенный «из обломков выброшенной на берег шхуны» [21. С. 3]. Основой первого музейного собрания стала коллекция образцов животных и птиц, которые были добыты на территории Чукотки и изготовлены А.К. Седько. 25 июля 1935 г. он был принят на должность заведующего музеем по договору на два года [16. Д. 2. Л. 7]. В документах имеются некоторые записи, характеризующие условия работы музея. Питание в то время в Анадыре было по карточкам. Сохранились продовольственные карточки на имя А.К. Седько и работника музея Тенкеу [Там же. Д. 3 Л. 10-11]. Есть записки о выделении спирта музеем для нужд различных организаций, в том числе и для лабораторий школы [Там же. Д. 2. Л. 59-61].

С 1938 г. начался сбор предметов косторезного искусства и ботанических образцов. В это время директором музея был искусствовед А.А. Васильев. Он работал в музее всего год. Из воспоминаний его дочери известно, что А.А. Васильеву было 30 лет, а жене 24 года, когда они приехали вместе на Чукотку. Для молодых это было романтическое путешествие. А.А. Васильев много работал и принимал участие в разных мероприятиях, фотографировал. За время его работы в музее сохранились некоторые документы [Там же. Л. 53-55]. В них содержится переписка по вопросам конкурсов по декоративно-прикладному искусству, имеется информация о приглашении его на сбор гербария для музея.

А.А. Васильев писал картины с северной тематикой, которые, возможно, сохранились в зарубежных музеях. Одна из его картин под названием «Из тундры», написанная в 1939 г., передает настроения того времени в п. Анадырь. По воспоминаниям дочери А.А. Васильева, он хотел рассказать «о людях, еще не приобщенных к новой жизни, но уже интересующихся ею. В экзотических одеждах, уставшие от лишений и недоедания, но наслышанные о светлой, еще неизведанной жизни, прибыли они с окраин Чукотки “присмотреться", “прицениться". А.А. Васильев достаточно тонко дает характеристику разным настроениям персонажей: это мечтательность расположенной слева на картине женщины, доброжелательное удивление находящегося в центре парня, пожилой чукчи» [22]. В 1939 г. супруги Васильевы с двухмесячной дочерью вернулись в Москву.

С конца 1930 - начала 1940-х гг. музеем производился сбор этнографических предметов. Сотрудником Чукотского окружного краеведческого музея Р.М. Рагтытваль зафиксированы сведения об этом в карточке научного описания музейного предмета «Подвеска» (ЧОКМ - 1875). В описании указано, что во время переезда музея в новое здание «в сарае старого музея хранилась часть фондов... среди них кухлянка шамана, приобретенная музеем в конце 1930 - начале 1940-х гг. в Чукотском районе» [23]. Музей переезжал в новое здание в 1969 г.; к тому времени собранные предметы этнографии, хранившиеся в сарае, были утрачены.
Музей открывался в любое время по просьбе посетителей. Руководству музея приходилось отстаивать режим работы музея в пользу посетителей. Об этом свидетельствует письмо-телеграмма заведующему культпросвет работы по Хабаровскому краю Л. Волковичу от директора музея Кругликовой [16. Д. 1. Л. 193]. В телеграмме она сообщает о том, что музей не может изменить график работы, в связи с тем, что «у нас большинство посетителей приезжих». Музей открыт «ежедневно кроме понедельника с 10 до 19». При изменении расписания «посетителей будет совсем мало, при этом для коренных жителей Чукотки и населения поселка музей открывается в любое время, в виду чего нет надобности в изменении графика работы» [Там же. Л. 193].

В повседневной жизни коренные жители называли места проживания по-своему, на родном языке. Например, «Анадырь» как поселок в бытовой речи до 1919 г. не звучал вообще. Был пост Ново-Мариинск, но и его местные жители называли по-разному. Жители села Марково, например, если ехали в НовоМариинск, говорили: «Еду на устье, был на устье», коренные жители тундры и побережья называли поселок Анадырь - Въен. Поэтому и музей, местные жители называли по-своему - «дом, в котором можно все увидеть» [21. С. 3]. В этом наблюдается особое восприятие коренным населением музея как нового места, представляющего важную и значимую для них информацию.

Фонды музея пополнялись медленно и стихийно, но к 1951 г. его собрание уже состояло из 703 предметов. Постоянными сотрудниками музея, как это часто бывает в небольших учреждениях культуры, были директор и уборщица.

В 1953-1955 гг. Чукотский окружной краеведческий музей стал проводить археологические раскопки. В этот период директором работал В.В. Нарышкин. Он обследовал древнее поселение на р. Канчалан. Однако он не был профессиональным археологом, и эти «любительские» раскопки скорее нанесли урон, чем пользу. Директор музея также беспокоился о сохранности экспонатов. Им были направлены письма в разные ведомственные учреждения с просьбами в решении хозяйственных проблем музея. Так, были направлены документы об установлении платы за посещения музея. Музею требовались деньги в связи с тем, что «большинство экспонатов отдела природы пришли в негодность и требуют замены, так как они простояли в экспозиции музея 15-20 лет» [16. Д. 2. Л. 121].

В июне 1955 г. в Чукотский окружной краеведческий музей приехал работать кандидат исторических наук Н.Н. Диков. К тому времени он имел опыт участия в археологических экспедициях под руководством известных ученых Б.Б. Пиотровского, А.П. Окладникова, М.Е. Массона. С 1956 по 1960 г. Н.Н. Диков ежегодно организовывал и проводил археологические экспедиции музея. Первоначально перед экспедицией стояла задача найти максимальное количество следов древней культуры, определить этническую принадлежность древних народов. Разведывательные экспедиции 1956-1958 гг. проводились 
во внутриконтинентальной части Чукотки и районах морского побережья. Археологом были исследованы крупные реки, озера, древние поселения, стоянки и могильники на побережье Чукотского полуострова. Предварительные отчеты этих экспедиций публиковались в «Записках Чукотского краеведческого музея», издание которого было начато благодаря инициативе директора музея. Вклад Н.Н. Дикова известен мировому научному сообществу, и он по достоинству оценен исследователями [24. С. 5-33].

В полевых дневниках директор музея Н.Н. Диков отмечает особенности проведения археологических разведок на Чукотке, приводит описания поселений, событий, дает информацию о сборе археологических предметов. Большой интерес представляют сообщения, полученные им от коренных жителей, заметки по взаимодействию исследователя с жителями по вопросам сохранения памятников древней культуры. Для проведения экспедиций привлекались проводники коренные жители, которые знали тундру, местность, море и реки. Директору музея рассказывали легенды, делились знаниями и мнениями. Его всегда гостеприимно встречали, предлагали ночлег в традиционном жилье. Слушали его рассказы с интересом.

Во время одной из экспедиций Н.Н. Диков встретился с пожилым чуванцем И.Г. Собольковым, жившем на реке Анадырь с 1910 г. И.Г. Собольков подтвердил данные о древнем поселении на берегу реки Анадырь. Чуванец рассказал археологу о другой древней стоянке на левом берегу реки Майн. Н.Н. Диков так охарактеризовал пожилого информанта: «Иван Гаврилович, истинный патриарх этого рыбачьего, отрезанного от большого мира крохотного посёлочка, был хранителем всех местных преданий» [21. С. 13]. В одной из дневниковых записей он отмечает: «Вчера вечером провел в яранге беседу по истории Чукотки. Рассказывал, что люди на Земле появились сотни лет назад и что были они сперва почти как звери. У всех это вызвало удивление. Говорил я, что Чукотка была заселена людьми уже несколько тысяч лет назад, и что прежде жилось им очень плохо: они не имели домашних оленей и занимались только охотой и рыбной ловлей [25. С. 141]». Он так же рассказывал о ближайших перспективах советского государства по освоению Земли и космоса. Его беседы вызывали большой интеpec у жителей стойбища. С собой у Н.Н. Диков всегда были книги или фотографии, он показывал эти материалы коренным жителям. В этот раз он показал обитателям стойбища книгу «Труды Института этнографии» (том XXXV, 1957 г.) с картинками и фотоснимками из чукотского быта [Там же. С. 142].

В селах жители приносили Н.Н. Дикову археологические находки, особенно дети [Там же. С. 144]. В селе Нунямо директор музея познакомился с мальчиком, в настоящее время пенсионер М.А. Зеленский. Он передал ему археологическую коллекцию, которую сам собрал на местах древних поселений [Там же. С. 146]. На мероприятии в Музейном центре «Наследие Чукотки» (г. Анадырь) М.А. Зеленский рассказал об этом случае, представил фотографию, сделанную Н.Н. Диковым, и добавил, что в дальнейшем археолог приглашал его на раскопки в свои экспедиции [26].

Так, в полевых условиях проходило общение директора музея и коренных жителей Чукотки, которых он старался привлечь к пониманию значимости их культуры, к сохранению памятников истории и культуры. Сам он все больше проникался к коренным жителям и к необходимым в суровых условиях жизненным правилам. «Сидя в байдаре, я все размышляю об этом удивительном народе. Все шокирующие нас обычаи чукчей, вернее, бытовые привычки, о которых со смаком любят писать многие, не хуже многих наших привычек и хороши тем, что вполне естественны, а иногда просто необходимы. Суровая жизнь вынуждает одеваться чукчей в шкуры. Некоторым это кажется диким, но поживешь в тундре и убедишься, что только такая одежда спасет человека от ужасного холода, и сам залезешь в шкуры. Это лучшая одежда на Севере. На морском побережье и в континентальных районах чукчи живут оседло и вполне благоустроенно» [25. С. 138]. Внимательность и уважение директора музея к традиционной культуре северных народов способствовали обмену культурными навыками и опытом между приезжим населением и местными жителями.

По музейным формам, которые составляли основную информацию о статистике посетителей в музее, можно проследить движение посетителей. В 1953 г. Чукотский краеведческий музей посетило 5190 человек [16. Д. 2. Л. 122]. Увеличение количества посетителей, при небольшой численности населения поселка Анадырь, объясняется тем, что посетителями являлась молодежь, обучающаяся в педучилище, в школе колхозных кадров, служащие различных организаций, приезжающие в командировки.

В результате проведенного исследования можно констатировать, что 1930-1950-е гг. стали важным этапом не только в становлении первого на Чукотке государственного музея, но и в культурной роли музейной работы в этом регионе. Для местного сообщества музей стал новой организационной формой сохранения предметов истории, культуры и реальности. За короткий период музей пополнился уникальными предметами истории и культуры коренных народов Севера. Этому способствовали активная позиция директоров музея и их профессиональная деятельность. Коренное население, участвовавшее в музейных археологических экспедициях, вносило вклад в поисках древних культур. Многие археологические стоянки были открыты благодаря знаниям коренных жителей. Взаимоотношения музейных сотрудников и местного сообщества наполняли опыт представителей традиционных культур новыми идеями и расширяли их кругозор. Музейные сотрудники из числа северных этносов пришли работать в музей и стали этнографами, которые уже с научной точностью описывали предметы традиционной культуры, ставили экспозиции. Все это способствовало развитию первого и единственного государственного музея на Чукотке. 


\section{ЛИТЕРАТУРА}

1. Богораз В. Г. Чукчи: Материальная культура / отв. ред. И.С. Вдовин. 2-е изд. М. : Книжный дом «ЛИБРОКОМ», 2011. 264 с.

2. Иохельсон В.И. Юкагиры и юкагиризированные тунгусы / пер. с англ. В.Х. Иванова, З.И. Иванова-Унаровой. г. Новосибирск : Наука, 2005. $675 \mathrm{c}$.

3. Леонтьев В.В. По земле древних кереков. Записки этнографа. г. Магадан : Книж. изд-во, 1976. 231 с.

4. История Чукотки с древнейших времен до наших дней / под рук. и общ. науч. ред. Н.Н. Дикова. М. : Мысль, 1989. 492 с.

5. Вдовин И.С. Очерки истории и этнографии чукчей. М.; Л. : Наука, 1965. 404 с.

6. Дьячкова Г.С. Этнокультурные процессы у чукчей в ХХ в. : автореф. дис. ... канд. ист. наук. М., 2011.171 с.

7. Чукотское и эскимосское искусство XIX-XX вв. (из собрания музея). Каталог / авт.-сост. А.К. Фисина. М. : Родник, 1995.126 с.

8. Кузнецова В.Г. Материалы по праздникам и обрядам амгуэмских оленных чукчей // Сибирский этнографический сборник. М.; Л. : Наука, 1957. Вып. 2. С. 264-326.

9. Широков Ю.А. Чукотская-эскимосская резная кость в Магаданском областном краеведческом музее // Краеведческие записки / редкол.: А.В. Беляева (отв. ред.) и др. Магадан : Книж. изд-во, 1977. Вып. ХІ. С. 82-95.

10. Музейное дело России / под ред. М.Е. Каулен. (отв. ред.), И.М. Коссовой, А.А. Сундиевой. М. : Изд-во «ВК», 2006.614 с.

11. Рубан Н.И. Советская власть и музейное строительство на Дальнем Востоке России (1920-1930-е гг.). Хабаровск : Хабаров. краевой краевед. музей им. Н.И. Гродекова, 2002. 215 с.

12. Станюкович Т.В. Этнографическая наука и музей. Л. : Наука, 1978. 288 с.

13. Чурилова Л.А. Роль музея в сохранении и развитии культуры народностей Севера (1917-1980-е гг.) (На материалах народностей Севера Средней Сибири) : автореф. дис. ... канд. ист. наук. М., 1991. 14 с.

14. Романова И.И. Развитие музейного дела на Чукотке (культурно-исторический анализ) : дис. ... канд. культурологии. СПб., 2008. 188 с.

15. Нефедова С.П. Культурное строительство на Чукотке (1917-1958 гг.) // Из истории промышленного и культурного строительства Чукотки. г. Магадан : Книж. изд-во, 1971. 160 с.

16. Государственный архив Чукотского автономного округа. Ф. Р-208.

17. Краткий справочник по фондам Государственного архива Чукотского автономного округа / Отдел по делам архивов Аппарата Губернатора и Правительства Чукотского АО. г. Анадырь : «Крайний Север», 2005. 104 с.

18. Володарская Е.Е. Возникновение и становление Камчатского областного краеведческого музея (1911-1934) // Краеведческие записки Камчатского областного краеведческого музея. г. Петропавловск-Камчатский, 2002. Вып. 12. 228 с.

19. Краткий путеводитель по выставке «Чукотское общество». / сост. проф. В.Г. Богораз-Тан. г. Л. : Издательство Академии наук СССР, 1934. $24 \mathrm{c}$.

20. Рига И.Г. 70 лет окружному музею, а так же о первом препараторе и собирателе // Крайний Север. Анадырь : Изд-во «Крайний Север», 2005. 29 июля. № 29. С. 15.

21. Диков Н.Н. По следам древних костров. Археологи идут по Чукотке. г. Магадан : Книж. изд-во, 1960.106 с.

22. Воспоминания Н.A. Васильевой. URL: http://www.na-vasilieva.ru/vasilev_aleksej_aleksandrovich_posle_ucheby_pered_moldaviej_ monografija_vasilevoj_n_a/ (дата обращения: 21.05.2018 г.).

23. Церковникова Е.А. Из опыта составления каталога одежды коренных народов Севера (на примере фондовых коллекций Музейного Центра «Наследие Чукотки» // VII Конгресс этнографов и антропологов России : докл. и выступления. Саранск, 9-14 июля 2007 г. / редкол.: В.А. Тишков [и др.]; НИИ гуманитар. наук при Правительстве Мордовия. Саранск, 2007. С. 420.

24. Диковские чтения : материалы науч.-практ. конф., посвящ. 75-летию со дня рождения чл.-кор. РАН Н.Н. Дикова. Магадан : СВКНИИ ДВО РАН, 2001. $276 \mathrm{c}$.

25. Диков Н.Н. Древние костры Камчатки и Чукотки. 15 тысяч лет истории. г. Магадан : Книж. изд-во, 1969. 256 с.

26. Полевые материалы автора. Запись М.А. Зеленского от 15.05.2018 г. г. Анадырь.

Статья представлена научной редакцией «История» 29 мая 2019 г.

Interaction of the Museum and the Local Community in Chukotka in the 1930s-1950s

Vestnik Tomskogo gosudarstvennogo universiteta - Tomsk State University Journal, 2020, 450, 185-190.

DOI: $10.17223 / 15617793 / 450 / 23$

Ekaterina A. Tserkovnikova, North-East Interdisciplinary Scientific Research Institute of Far East Branch of the Russian Academy of Sciences (Magadan, Russian Federation). E-mail: etserkovnikova1@yandex.ru

Keywords: national cultural tradition; need for museum; indigenous people of North; Soviet period; archaeological expeditions; Chukotka.

The aim of this article is to present and analyse interactions between museum specialists and the indigenous people of Chukotka in the 1930s-1950s. To achieve this aim, the article solves the following problems: analyses history sources of creating the first museum in Chukotka and describes the features of the interaction of cultures during the first museum's archaeological expeditions. The history of museum work shows how a new environment created the need for the preservation of the traditional culture of the northern peoples. This case study allows re-evaluating directions of museum work at present. In this article, the history of the first museum in Chukotka was reconstructed based on the sources from the State Archive of Chukotka Autonomous Okrug. Archive materials allowed analysing the information about museum activities throughout the mentioned period and learning about the life and work of its founders. Unfortunately, visitor statistics are only represented partially in the archive materials, due to the loss of documents or a negligent maintenance of the archives under the changing management. Correspondence of the museum with other museums in the country reveals the general direction of all the museums in the Soviet Union at the time. Memoirs of the relatives of museum workers, which the author had found in the press or on the internet, allowed assessing workers' professional attitude towards interacting with other people and provide an understanding of the social atmosphere of the time. The sources also allowed analysing the role of the museum in archaeological expeditions in the 1950s. The preserved diary notes of the expedition members contain information about the kind of communication with the indigenous peoples during professional and daily situations. Collaboration of the representatives of different cultures, education and generations formed the indigenous peoples' special attitude towards collecting and preserving of cultural artifacts. The author concludes that museums became a new form of preserving cultural heritage in the region, and became the centre of collecting knowledge about the ancient history of the humankind, the nature of the region and the traditional culture of the indigenous peoples. Communication of the museum with local communities and other categories of visitors has its peculiarities and a long history. Currently, the older generations of the indigenous peoples of the North are the keepers of traditional knowledge, and can act as consultants or experts in ethnographic issues in the museum. 


\section{REFERENCES}

1. Bogoraz, V.G. (2011) Chukchi: Material'naya kul'tura [The Chukchi: Material Culture]. 2nd ed. Moscow: Knizhnyy dom "LIBROKOM".

2. Jochelson, W. (2005) Yukagiry i yukagirizirovannye tungusy [The Yukaghir and Yukaghirized Tungus]. Translated from English by V.Kh. Ivanov, Z.I. Ivanova-Unarova. Novosibirsk: Nauka.

3. Leont'ev, V.V. (1976) Po zemle drevnikh kerekov. Zapiski etnografa [On the Land of Ancient Kereks. Notes of an Ethnographer]. Magadan: Knizh. izd-vo.

4. Dikov, N.N. (ed.) (1989) Istoriya Chukotki s drevneyshikh vremen do nashikh dney [The History of Chukotka From Ancient Times to the Present Day]. Moscow: Mysl'.

5. Vdovin, I.S. (1965) Ocherki istorii i etnografii chukchey [Essays on the History and Ethnography of the Chukchi]. Moscow; Leningrad: Nauka.

6. D'yachkova, G.S. (2011) Etnokul'turnye protsessy u chukchey $v$ XX v. [Ethnocultural Processes in the Chukchi in the 20th Century]. Abstract of History Cand. Diss. Moscow.

7. Fisina, A.K. (1995) Chukotskoe i eskimosskoe iskusstvo XIX-XX vv. (iz sobraniya muzeya). Katalog [The Chukchi and the Eskimo Art of the 19th 20th Centuries (From the Museum Collection). A Catalogue]. Moscow: Rodnik.

8. Kuznetsova, V.G. (1957) Materialy po prazdnikam i obryadam amguemskikh olennykh chukchey [Materials on Holidays and Ceremonies of the Amguema Deer Chukchi]. In: Sibirskiy etnograficheskiy sbornik [Siberian Ethnographic Collection]. Is. 2. Moscow; Leningrad: Nauka. pp. 264326.

9. Shirokov, Yu.A. (1977) Chukotskaya-eskimosskaya reznaya kost' v Magadanskom oblastnom kraevedcheskom muzee [The Chukchi-Eskimo Carved Bone in the Magadan Regional Museum of Local Lore]. In: Belyaeva, A.V. et al. (eds) Kraevedcheskie zapiski [Local Lore Notes]. Is. 11. Magadan: Knizh. izd-vo. pp. 82-95.

10. Kaulen, M.E. (ed.) (2006) Muzeynoe delo Rossii [Museum Studies in Russia]. Moscow: Izd-vo "VK".

11. Ruban, N.I. (2002) Sovetskaya vlast' i muzeynoe stroitel'stvo na Dal'nem Vostoke Rossii (1920-1930-e gg.) [Soviet Power and Museum Construction in the Far East of Russia (1920-1930s)]. Khabarovsk: Khabarov. kraevoy kraeved. muzey im. N.I. Grodekova.

12. Stanyukovich, T.V. (1978) Etnograficheskaya nauka i muzey [Ethnographic Science and Museum]. Leningrad: Nauka.

13. Churilova, L.A. (1991) Rol' muzeya v sokhranenii i razvitii kul'tury narodnostey Severa (1917-1980-e gg.) (Na materialakh narodnostey Severa Sredney Sibiri) [The Role of the Museum in the Preservation and Development of the Culture of the Peoples of the North (1917-1980s) (Based on the Materials of the Peoples of the North of Central Siberia)]. Abstract of History Cand. Diss. Moscow.

14. Romanova, I.I. (2008) Razvitie muzeynogo dela na Chukotke (kul'turno-istoricheskiy analiz) [The Development of Museum Work in Chukotka (A Cultural-Historical Analysis)]. Culture Studies Cand. Diss. St. Petersburg.

15. Nefedova, S.P. (1971) Kul'turnoe stroitel'stvo na Chukotke (1917-1958 gg.) [Cultural Construction in Chukotka (1917-1958)]. In: Krushanov, A.I. \& Ezhov, V.A. (eds) Iz istorii promyshlennogo i kul'turnogo stroitel'stva Chukotki [From the History of Industrial and Cultural Construction of Chukotka]. Magadan: Knizh. izd-vo.

16. State Archive of Chukotka Autonomous Okrug. Fund R-208. (In Russian).

17. Department for Archives of the Office of the Governor and Government of Chukotka Autonomous Okrug. (2005) Kratkiy spravochnik po fondam Gosudarstvennogo arkhiva Chukotskogo avtonomnogo okruga [A Short Reference to the Funds of the State Archive of Chukotka Autonomous Okrug]. Anadyr: "Krayniy Sever".

18. Volodarskaya, E.E. (2002) Vozniknovenie i stanovlenie Kamchatskogo oblastnogo kraevedcheskogo muzeya (1911-1934) [The Emergence and Formation of the Kamchatka Regional Museum of Local Lore (1911-1934)]. Kraevedcheskie zapiski Kamchatskogo oblastnogo kraevedcheskogo muzeya. 12.

19. Bogoraz-Tan, V.G. (1934) Kratkiy putevoditel' po vystavke "Chukotskoe obshchestvo" [A Short Guide to the Exhibition "Chukchi Society"]. Leningrad: USSR AS.

20. Riga, I.G. (2005) 70 let okruzhnomu muzeyu, a tak zhe o pervom preparatore i sobiratele [70 Years to the District Museum, and on the First Preparator and Collector]. Krayniy Sever. 29 July. 29. p. 15.

21. Dikov, N.N. (1960) Po sledam drevnikh kostrov. Arkheologi idut po Chukotke [Following the Trails of Ancient Bonfires. Archaeologists Are Walking Around Chukotka]. Magadan: Knizh. izd-vo.

22. Vasil'eva, N.A. (n.d.) Vospominaniya N.A. Vasil'evoy [Memoirs of N.A. Vasilyeva]. [Online] Available from: http://www.navasilieva.ru/vasilev_aleksej_aleksandrovich_posle_ucheby_pered_moldaviej_monografija_vasilevoj_n_a/. (Accessed: 21.05.2018 g.).

23. Tserkovnikova, E.A. (2007) [From the Experience of Compiling a Catalogue of Clothing of the Indigenous Peoples of the North (On the Example of Stock Collections of the Museum Centre "Heritage of Chukotka"]. VII Kongress etnografov $i$ antropologov Rossii [VII Congress of Ethnographers and Anthropologists of Russia]. Proceedings. Saransk. 9-14 July 2007. Saransk: [s.n.]. p. 420. (In Russian).

24. North-East Interdisciplinary Scientific Research Institute of the Far Eastern Branch of the Russian Academy of Sciences. (2001) Dikovskie chteniya [Dikov Readings]. Proceedings of the International Conference Dedicated to the 75th Anniversary of N.N. Dikov, a RAS Member. Magadan: North-East Interdisciplinary Scientific Research Institute of the Far Eastern Branch of the Russian Academy of Sciences.

25. Dikov, N.N. (1969) Drevnie kostry Kamchatki i Chukotki. 15 tysyach let istorii [Ancient Bonfires of Kamchatka and Chukotka. 15 Thousand Years of History]. Magadan: Knizh. izd-vo.

26. Tserkovnikova, E.A. (2018) Field Materials. Record of M.A. Zelensky made on 15 May 2018. Anadyr. (In Russian).

Received: 29 May 2019 